\title{
Desempenho de doadoras leiteiras mestiças F1 (Gir x Holandês) no sistema de produção in vitro de embriões
}

\author{
[Performance of dairy crossbred F1 donnors (Gir x Holstein) in the production \\ system in vitro embryo] \\ J.G.V. Grázia' ${ }^{1}$, R.O. Silveira ${ }^{2}$, E.C.M. Pereira ${ }^{3}$, G.M. Santos ${ }^{2}$ \\ ${ }^{1}$ Universidade Federal de Minas Gerais \\ ${ }^{2}$ Faculdade de Ciências Médicas e da Saúde - Univiçosa \\ ${ }^{3}$ Universidade Federal de Uberlândia
}

\begin{abstract}
RESUMO
O Brasil atualmente é detentor do terceiro maior rebanho de vacas leiteiras do mundo, composto, em sua maioria, de animais mestiços F1 (Gir X Holandês), os quais são bem adaptados às áreas tropicais. O objetivo do presente estudo foi investigar a eficiência da ovum pick-up (OPU) e da produção in vitro de embriões oriundos de doadoras Girolando com sêmen sexado de touros provenientes de duas raças, Gir e Holandesa. Foram utilizados dados referentes a 232 animais de diversos rebanhos, totalizando 4334 oócitos recuperados. Os oócitos foram classificados, e as estruturas viáveis (GI, GII e GIII) foram utilizadas para produção in vitro de embriões (PIVE). Foi observada uma média de oócitos recuperados para as doadoras F1 de 18,14 $\pm 1,33$. Além disso, notou-se que não houve diferença entre os dois cruzamentos utilizados, considerando média de total de embriões $(4,96 \pm 0,40$ e $6,56 \pm 0,76)$ para o cruzamento F1 X HPB (Holandês preto e branco) e F1 X Gir, respectivamente. Portanto, as doadoras F1 apresentaram potencial como doadoras de oócitos no sistema de produção in vitro de embriões, independentemente da raça do touro cujo sêmen foi utilizado.
\end{abstract}

Palavras-chave: Girolando, OPU, PIVE

\begin{abstract}
Brazil currently has the third largest herd of dairy cattle in the world, composed mainly by F1 crossbreed animals (Gyr x Holstein), which are well adapted to tropical areas. The aim of this study was to evaluate the efficiency of Girolando donors in OPU and in vitro production of embryos (IVEP) using sexed semen of bulls from two breeds, Gyr and Holstein. We used data from 232 animals coming from different herds and the total of recovered oocytes was 4334. The oocytes were classified according to their viability and the viable ones (GI, GII and GIII) were used for IVP. The average of oocyte recovery from F1 donors was 18.14 \pm 1.33 . There was no difference on the average of embryos considering the crossing F1 X Holstein (4.96 \pm 0.40$)$ and F1 X Gyr (6.56 \pm 0.76$)$. In conclusion, F1 donors showed a potential for being oocyte donors in the system of in vitro production of embryos, regardless the breed of the bull.
\end{abstract}

Keywords: Girolando, OPU, IVEP

\section{INTRODUÇ̃̃̃O}

O agronegócio do leite possui um papel de extrema importância na sociedade, uma vez que o produto final dessa atividade, o leite, é um alimento único por seu valor nutritivo e sua composição. O rebanho do continente americano é considerado o segundo maior produtor de leite do mundo, depois apenas da Europa. Já o Brasil ocupa a posição de quinto maior produtor mundial de leite, com aproximadamente 25 bilhões de litros. Além disso, o país possui o terceiro maior rebanho de vacas leiteiras do mundo, composto, em sua maioria, da raça Girolando (Nanzer, 2010).

Recebido em 27 de março de 2015 
A reprodução animal se torna cada vez mais alvo de estudos e aperfeiçoamentos, com o objetivo de se obterem, como produto final, doadoras com alta eficiência reprodutiva, garantindo e acelerando, assim, a produção de animais com potencial genético de destaque (Machado et al., 2012).

Nos últimos anos, a biotécnica de eleição para maximizar o número de descendentes dos melhores animais e acelerar o progresso genético dos rebanhos tem sido a produção in vitro de embriões (PIVE), associada à aspiração folicular guiada por ultrassom, da sigla inglesa ovum pickup (OPU) (Varago et al., 2008). Somada a isso, a possibilidade de uso de sêmen sexado se tornou uma grande vantagem, principalmente para os criadores de gado leiteiro, permitindo sobremaneira a produção de um grande número de fêmeas, sabidamente importante para a indústria de lácteos (Trigal et al., 2012).

As raças zebuínas especializadas na produção de leite, como a Gir, possuem normalmente maior quantidade de complexos cumulus-oócitos (CCO) recuperados por sessão de aspiração folicular em relação aos animais taurinos, tal como a raça Holandesa (Pontes et al., 2010; Viana et al., 2004). Além disso, animais da raça zebuína são considerados bem adaptados a áreas tropicais, pois produzem grande quantidade de leite quando submetidos a condições adversas, como altas temperaturas, parasitas e pastagem pobre em nutrientes. Por essas características e pela boa eficiência reprodutiva, o interesse nessa raça vem crescendo nos últimos anos. Essas características são mantidas no animal mestiço (Gir X Holandês), usualmente denominado "Girolando", que é o gado leiteiro mais popular nas Américas Central e do Sul (Pontes et al., 2010).

O objetivo do presente estudo foi investigar a eficiência da OPU e da produção in vitro de embriões oriundos de doadoras F1 (Gir X Holandês) com sêmen sexado de touros de duas raças puras, Gir e Holandês.

\section{MATERIAL E MÉTODOS}

O estudo foi realizado com os resultados do laboratório comercial de produção in vitro de embriões bovinos, Ativa Embriões, localizado em Juiz de Fora, MG. Foram utilizados dados de vacas F1 (Gir X Holandês) (n=232), provenientes de diferentes rebanhos das regiões da Zona da Mata de Minas Gerais e Campo das Vertentes e Sul do estado do Rio de Janeiro. A totalidade desses animais era examinada previamente, e estes se apresentavam com histórico reprodutivo (idade, número de aspirações, taxa de produção de oócitos e embriões) considerado normal.

A aspiração folicular foi realizada com auxílio de equipamento de ultrassom portátil equipado com transdutor setorial de $7,5 \mathrm{MHz}$, adaptado para exame intravaginal e com guia para agulha de biópsia (Aquila, Esaote-Pie Medical, Maastricht, Holanda). Agulhas descartáveis $(20 \mathrm{G})$ foram acopladas a um sistema de vácuo com pressão aproximada de $50 \mathrm{mmHg}$ ou equivalente ao fluxo de $11 \mathrm{~mL}$ por minuto. O líquido folicular e os complexos cumulus-oócitos (CCO) foram aspirados para um tubo de $50 \mathrm{~mL}$ contendo $10 \mathrm{~mL}$ de Dulbecco's PBS (DPBS) (Nutricell, Campinas, SP, Brasil), suplementado com 5\% de soro fetal bovino (Nutricell) e 100UI de heparina sódica (Liquemine, Roche, Basileia, Suíça), e previamente aquecido a $36^{\circ} \mathrm{C}$. Todos os $\mathrm{CCO}$ recuperados $(n=4334)$ foram mantidos em criotubos (TPP; capacidade de 1,5mL), devidamente identificados com meio tamponado, e transportados para o laboratório no intervalo de três a 12 horas a $37^{\circ} \mathrm{C}$. Ao chegarem ao laboratório, os $\mathrm{CCO}$ foram classificados segundo Viana et al. (2004) (Tab. 1), por um mesmo indivíduo. Somente oócitos considerados viáveis foram submetidos ao processo de maturação in vitro (MIV).

Todos os animais selecionados para a aspiração folicular do presente estudo não tiveram a utilização de protocolos hormonais para a sincronização do cio. As doadoras tiveram os oócitos recuperados independentemente do dia do ciclo estral. 
Tabela 1. Classificação dos complexos cumulus-oócitos recuperados por punção folicular guiada por ultrassom

\begin{tabular}{|c|c|}
\hline Classificação & Descrição \\
\hline Grau I & $\begin{array}{l}\text { CCO compacto, mais do que três camadas de células do cumulus e oócito } \\
\text { com citoplasma homogêneo }\end{array}$ \\
\hline Grau II & $\begin{array}{l}\mathrm{CCO} \text { compactos, com três ou menos camadas de células do cumulus, ou } \\
\text { oócito com citoplasma levemente heterogêneo }\end{array}$ \\
\hline Grau III & $\begin{array}{l}\text { Oócitos mostrando remoção completa das células do cumulus de menos que } \\
1 / 3 \text { da superfície da zona pelúcida }\end{array}$ \\
\hline $\begin{array}{l}\text { Desnudo e/ou } \\
\text { degenerado }\end{array}$ & $\begin{array}{l}\text { Oócitos com nenhuma célula do cumulus sobre a maior parte da zona } \\
\text { pelúcida e/ou vacuolização, retração do citoplasma }\end{array}$ \\
\hline Cumulus expandido & CCO mostrando expansão das células do cumulus \\
\hline
\end{tabular}

Adaptado de Viana et al., 2004.

A MIV dos CCO foi realizada em meio TCM 199 (Gibco) acrescido de $10 \%$ de soro fetal bovino, $120 \mu \mathrm{L}$ de $\mathrm{FSH}, 120 \mu \mathrm{L}$ de $\mathrm{LH}$, $4.4 \mathrm{mg} / \mathrm{mL}$ de piruvato e $120 \mu \mathrm{L}$ de antibiótico, em gotas de $70 \mu \mathrm{L}$, mantido em estufa incubadora a $38,8^{\circ} \mathrm{C}$, com $5 \%$ de $\mathrm{CO}_{2}$ em ar atmosférico e $95 \%$ de umidade, por 24 horas. Os oócitos de cada doadora foram colocados em gotas separadas em grupos de um a 30 por gota, conforme a produção individual dos animais.

Os CCO maturados foram fecundados com sêmen de touros previamente provados. Para a preparação dos espermatozoides, foi utilizado o método do gradiente de Percoll (Invitrogen ${ }^{\circledR}$ ). A fecundação foi realizada na gota de $60 \mu \mathrm{L}$ de meio FIV contendo heparina e PHE, a dose inseminante utilizada foi de aproximadamente $2 \times 10^{6}$ espermatozoides $/ \mathrm{mL}$, sob óleo mineral, por um período de aproximadamente de 18-22 horas, nas mesmas condições atmosféricas da maturação da etapa anterior.

Para o cultivo dos zigotos presumíveis, foi utilizado CR4aa (Invitrogen ${ }^{\circledR}$ ) contendo soro fetal bovino e BSA. Os embriões $(n=1219)$ foram cocultivados com células da granulosa nas mesmas condições da fecundação, no entanto, em gotas de $50 \mu \mathrm{L}$, sob óleo mineral. Após 72 horas do início do cultivo, foi realizado o primeiro feeding, que consiste na troca de $50 \%$ do meio e na taxa de clivagem avaliada. No sexto dia, foi realizado novamente o procedimento feeding. No sexto e sétimo dias após a fecundação, a taxa de blastocisto foi avaliada por meio da visualização dos embriões, utilizando-se microscópio estereoscópio (Nikon SMZ 745) sob aumento de 40x.

Os dados do trabalho foram submetidos ao teste de ANOVA, e diferenças entre os grupos comparadas pelo teste de Tukey. Diferenças percentuais foram comparadas por qui-quadrado.

\section{RESULTADOS E DISCUSSÃO}

Para caracterizar as doadoras, a primeira avaliação foi em relação à eficiência na PIVE comparando-se o rendimento de produção de oócitos obtidos por meio de aspiração folicular (Tab. 2), bem como a capacidade de produção in vitro de embriões (Tab. 3). A média de CCO total dos animais $\mathrm{F} 1(18,14 \pm 1,33)$ foi similar à produção de CCO da raça Gir $(19,1 \pm 0,9)$ e superior à produção da raça Holandesa $(13,3 \pm 0,6)$ encontradas por Grázia et al. (2013), e superior à encontrada por Oliveira et al. (2013) nas raças Gir $(11,96 \pm 0,69)$ e Holandesa $(6,76 \pm 0,33)$. Essa diferença pode ser explicada pelas diversas diferenças na físiologia ovariana entre os animais zebuínos e taurinos, como maior número de ondas de crescimento folicular, menor persistência e diâmetro do folículo dominante no momento da divergência e maior número de folículos por onda de crescimento nos animais zebuínos (Viana et al., 2004), consequentemente o número médio de $\mathrm{CCO}$ aspirados é superior ao daqueles aspirados nas raças taurinas. Neste estudo, é bem definida que a característica de maior produção de CCO dos animais zebuínos, mais especificamente da raça Gir, foi mantida na geração $\mathrm{F} 1$, sendo essa uma característica de interesse no processo de OPU/PIVE. 
Tabela 2. Parâmetros da aspiração folicular (CCO GI, CCO GII, CCO GIII, CCO viáveis, \% de viáveis, degenerados e total de estruturas) das doadoras mestiças F1 (Gir X Holandesa)

\begin{tabular}{|c|c|}
\hline \multicolumn{2}{|c|}{ Aspiração folicular } \\
\hline Parâmetros & F1 \\
\hline CCO GI & $0,44 \pm 0,14$ \\
\hline CCO GII & $1,05 \pm 0,28$ \\
\hline CCO GIII & $9,93 \pm 0,84$ \\
\hline CCO viáveis & $11,37 \pm 0,84$ \\
\hline \% de viáveis & 63 \\
\hline Degenerados & $6,77 \pm 0,67$ \\
\hline Total de estruturas & $18,14 \pm 1,33$ \\
\hline
\end{tabular}

Tabela 3. Parâmetros de produção de embrião in vitro (clivados, taxa de clivagem, embriões no sétimo dia de CIV, taxa de D7, embriões no oitavo dia de CIV, taxa de D8, total de embriões e taxa total de embriões) das doadoras mestiças F1 (Gir X Holandesa)

\begin{tabular}{lcc}
\hline & Produção in vitro de embriões & \\
\hline Parâmetros & F1 X HPB & F1 X Gir \\
\hline Clivados & $9,13 \pm 0,50 \mathrm{a}$ & $10,4 \pm 0,87 \mathrm{a}$ \\
Taxa de clivagem (\%) & $84 \mathrm{a}$ & $90^{\mathrm{a}}$ \\
D7 & $3,71 \pm 0,36 \mathrm{a}$ & $5 \pm 0,67 \mathrm{a}$ \\
Taxa de D7 (\%) & $33 \mathrm{a}$ & $43^{\mathrm{a}}$ \\
D8 & $0,83 \pm 0,12 \mathrm{a}$ & $1,4 \pm 0,24 \mathrm{a}$ \\
Taxa de D8 (\%) & $8 \mathrm{a}$ & $13^{\mathrm{a}}$ \\
Total de embriões & $4,96 \pm 0,40 \mathrm{a}$ & $6,56 \pm 0,76 \mathrm{a}$ \\
Taxa de embriões (\%) & $43 \mathrm{a}$ & $55^{\mathrm{a}}$ \\
\hline
\end{tabular}

*Raça materna $\mathrm{x}$ raça paterna.

Valores seguidos de letras diferentes na mesma linha diferem $(\mathrm{P}>0,05)$.

Adicionalmente, avaliou-se a raça do touro cujo sêmen foi utilizado para a fertilização dos oócitos. Dessa maneira, objetivou-se comparar se existem diferenças também no potencial de desenvolvimento in vitro dos $\mathrm{CCO}$ em função dos acasalamentos, utilizando-se touros das raças Holandesa e Gir como parâmetros. Observou-se que não houve diferença entre os dois acasalamentos nos parâmetros analisados (Tab. 3), o que corrobora os estudos de Nabhan (2011) e Saito (2006), cujos efeitos da raça do touro também não foram evidenciados, pois as taxas de blastocisto e de blastocisto eclodido não diferem entre os touros Gir e Holandês.

A produção de embriões utilizando como matriz doadoras mestiças F1 se mostrou viável quando comparadas as raças sabidamente eficientes na PIVE, apresentando média superior às doadoras da raça Holandesa (32,5\% acasaladas com touro HPB e 40,8\% acasaladas com touro Gir) e similar às doadoras da raça Gir $(55,4 \%$ acasaladas com touro Gir e $54,9 \%$ acasaladas com touro HPB) descritas por Grázia et al. (2013).

Os animais da geração F1 apresentam $50 \%$ de sangue Gir e 50\% de sangue Holandês, e o resultado inferior de produção in vitro de embriões do acasalamento F1 X HPB pode ser explicado por esses embriões apresentarem 75\% de sangue Holandês, raça que, segundo Camargo et al. (2007), apresenta menor competência no processo de PIVE quando comparada com animais zebuínos. Outra possível explicação seria o estresse térmico que também influencia na produção, diminuindo significativamente as taxas de blastocisto e de blastocisto eclodido, tanto para oócitos HPB fertilizados com sêmen Gir quanto fertilizados com sêmen HPB (Saito, 2006). Essa maior sensibilidade ao estresse térmico das raças taurinas está relacionada à menor adaptação dessas às condições climáticas em que a temperatura é mais elevada (Hansen, 2004), como é o caso das regiões onde o presente estudo foi realizado. 
Já os embriões provenientes do acasalamento F1 $\mathrm{X}$ Gir, que apresentam $25 \%$ de sangue Holandês e $75 \%$ de sangue Gir, possuem maior capacidade de produção in vitro de embriões. De acordo com Nabhan et al. (2011), embriões zebuínos são mais resistentes do que embriões mestiços (oócito taurino $\mathrm{x}$ sêmen zebuíno) e taurinos (HPB) desenvolvidos in vitro.

Para verificar a influência do sistema de cultivo na produção in vitro de embriões de doadoras mestiças F1, foram agrupados os animais de acordo com a sua taxa de produção de embriões.
Dessa maneira, quando se observou a eficiência do sistema de cultivo (Fig. 1), foi possível perceber que algumas doadoras alcançaram a produção máxima de embriões. Ao se manter o mesmo sistema de cultivo e se alterarem as doadoras e os touros, a variação na produção de embriões permaneceu com alguns indivíduos produzindo índices de $100 \%$ de embriões (21/232) enquanto outros não produziram embriões (30/232). Esse mesmo padrão de distribuição já foi encontrado para doadoras Gir e Holandesa (Grázia et al., 2013).

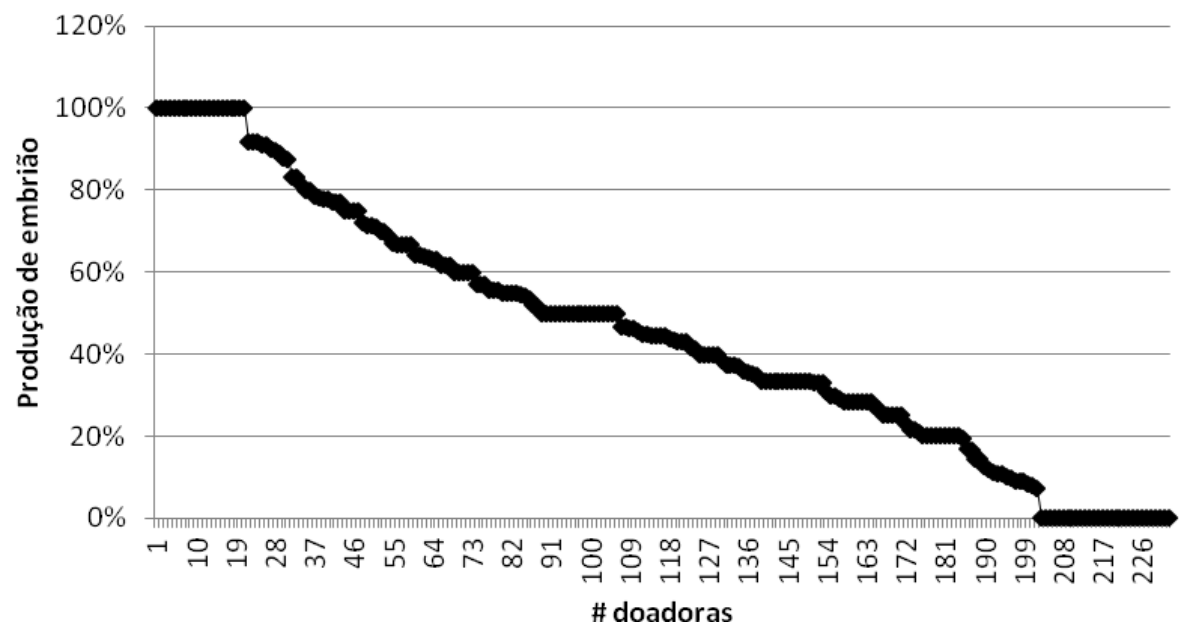

Figura 1. Distribuição das doadoras mestiças F1 (Gir X Holandês) baseada na produção de embrião (\%).

\section{CONCLUSÃO}

Vacas mestiças F1 (Gir X Holandês) apresentam potencial como doadoras de oócitos e eficiência no sistema de produção in vitro de embriões similar às vacas zebuínas, independentemente da raça do touro doador do sêmen utilizado. Dessa maneira, vacas F1 podem ser utilizadas como doadoras de oócito para PIVE, levando em consideração apenas a eficiência de produção de embriões in vitro.

\section{REFERÊNCIAS}

CAMARGO, L.S.; VIANA, J.H.M; RAMOS, A.A.; SERAPIÃO, R.V. et al. Developmental competence and expression of the Hsp 70.1 gene in oocytes obtained from Bos indicus and Bos taurus dairy cows in a tropical environment. Theriogenology, v.68, p.626-632, 2007.
GRAZIA, J.G.V.; ARASHIRO, E.K.N.; PALHÃO, M.P. et al. Is it possible to increase the efficiency of in vitro embryo production in Holstein by preselection of donors with great oocyte production. In: REUNIÃO ANUAL DA SOCIEDADE BRASILEIRA DE TECNOLOGIA DE EMBRIÕES, 27., 2013. Reprod. Dom. Anim.. v.10, p.526-526, 2013. (Resumo).

HANSEN, P. J. Physiological and cellular adaptations of zebu cattle to thermal stress. Anim. Reprod. Sci., v.82-83, p.349-360, 2004.

MACHADO, C.I.I.U.F.; GUIMARÃES, A.C.G.; GONÇALVES, C.G.M.; et al. Influência do sêmen de diferentes touros sobre as taxas de fecundação in vitro e desenvolvimento de embriões. In: SALÃO INTERNACIONAL DE ENSINO, PESQUISA E EXTENSÃO, 2012, Bagé. Anais ... Bagé: Universidade Federal do Pampa, 2012. v.4. 
NABHAN, T.; SATRAPA, R.A.; SIMÕES, R.A.L. et al. Influência da raça do touro (Bos indicus $\mathrm{x}$ Bos taurus) na tolerância ao estresse térmico calórico de embriões bovinos produzidos in vitro. Braz. J. Vet. Res. Anim. Sci., v.48, p.332-335, 2011.

NANZER, T.A.D.T. Produção de leite no Brasil e participação da genética Girolando com ênfase em reprodução. 2010. Disponível em: $<$ http://www.girolando.com.br/index.php?pagina sSite/tecnico,39>. Acessado em: 17 set. 2014.

OLIVEIRA, C.S. Produção in vitro de embriões bovinos F1 a partir de doadoras de oócitos da raça Gir Leiteiro e Holandesa. In: SIMPÓSIO BRASILEIRO DE MELHORAMENTO ANIMAL, 2013, Uberaba. Anais... Uberaba: SBMA, 2013. (Resumo).

PONTES, J.H.; SILVA, K.C.; BASSO, A.C. et al. Large-scale in vitro embryo production and pregnancy rates from Bos taurus, Bos indicus, and indicus-taurus dairy cows using sexed sperm. Theriogenology, v.74, p.1349-1355, 2010.
SAITO, D. Y. Estudo da influência da raça do touro (Bos indicus $x$ Bos taurus) na resistência de embriões bovinos ao estresse térmico calórico in vitro, no estágio inicial de desenvolvimento(Tudo em Itálico?). 2006. 42f. Trabalho de conclusão de curso (Graduação em Ciências Biológicas) - Instituto de Biociências, Universidade Estadual Paulista Júlio de Mesquita Filho, Botucatu, SP.

TRIGAL, B.; GÓMEZ, E.; CAAMAÑO, J.N. et al. In vitro and in vivo quality of bovine embryo in vitro produced with sex-sorted sperm. Theriogenology, v.78, p.1465-1475, 2012.

VARAGO, F.C.; MENDONÇA, L.F.; LAGARES, M.A. Produção in vitro de embriões bovinos: estado da arte e perspectiva de uma técnica em constante evolução. Rev. Bras. Reprod. Anim., v.32, p.100-109, 2008.

VIANA, J.H.M. Pre-synchronization of cows for cumulus oocyte complexes recover: Partial results. Act. Sci. Vet., v.31 p.187, 2004. 